\title{
A Cluster Randomized Trial of Sun Protection at Elementary Schools:
}

\section{Results from Year 2}

Richard G. Roetzheim, MD, MSPH, Kymia M. Love-Jackson, MBA, Seft G. Hunter, MA, JiHyun Lee, DrPH, Ren Chen, MD, MPH, Rania Abdulla, MA, and Kristen J. Wells, PhD, MPH Department of Family Medicine (Roetzheim, Love-Jackson, Hunter, Abdulla), Clinical and Translational Science Institute (Chen), Center for Evidence-Based Medicine and Health Outcomes Research (Wells), University of South Florida; H. Lee Moffitt Cancer Center \& Research Institute (Roetzheim, Lee, Abdulla), Tampa, Florida

\section{Abstract}

Background-Elementary schools are one potential venue for sun protection interventions that reduce childhood sun exposure.

Purpose-To assess Year-2 results from a cluster randomized trial promoting hat use at schools.

Design-Block randomization was used to assign intervention/control status to participating schools. Data were collected from 2006 to 2008 and analyzed in 2007-2010.

Setting/participants-Of the 24 schools in the School District of Hillsborough County, Florida enrolled, fourth-graders were targeted in the first year and followed through their 5th-grade year.

Intervention-Classroom sessions were conducted to improve sun protection knowledge, foster more positive attitudes about hat use, and change the subjective norm of wearing hats when at school.

Main outcome measures-Year-2 outcomes assessed included hat use at school (measured by direct observation), hat use outside of school (measured by self-report) and skin pigmentation and nevi counts (measured for a subgroup of 439 students).

Results-The percentage of students observed wearing hats at control schools remained unchanged during the 2-year period (range $0 \%-2 \%$ ) but increased significantly at intervention schools (2\% at baseline, $41 \%$ at end of Year 1, 19\% at end of Year 2; $p<0.001$ for intervention effect). Measures of skin pigmentation, nevi counts, and self-reported use of hats outside of school did not change during the study period.

Conclusions-This intervention increased use of hats at school through Year 2 but had no measurable effect on skin pigmentation or nevi. Whether school-based interventions can ultimately prevent skin cancer is uncertain.

@ 2011 American Journal of Preventive Medicine. Published by Elsevier Inc. All rights reserved.

Address correspondence to: Richard Roetzheim, MD, MSPH, Department of Family Medicine, University of South Florida, 12901 Bruce B. Downs Blvd., MDC 13, Tampa FL 33612. rroetzhe@ health.usf.edu.

This is a PDF file of an unedited manuscript that has been accepted for publication. As a service to our customers we are providing this early version of the manuscript. The manuscript will undergo copyediting, typesetting, and review of the resulting proof before it is published in its final citable form. Please note that during the production process errors may be discovered which could affect the content, and all legal disclaimers that apply to the journal pertain.

No financial disclosures were reported by the authors of this paper. 


\section{Introduction}

Childhood is an important period for sun protection because substantial lifetime sun exposure occurs during childhood ${ }^{1-4}$, and many skin cancers have been linked with childhood sun exposure..$^{5-7}$ The Sun Protection for Florida's Children (SPF) project was a defined, classroom-based intervention that emphasized the use of wide-brimmed hats when children were outdoors. The intervention targeted 4th-grade students in the first year of the study and continued with the same cohort of students through the subsequent 5th-grade school year. In the first year of follow-up, the SPF intervention increased the proportion of 4 th-grade children who wore hats while at school. ${ }^{8}$

The ability to sustain sun protection behaviors beyond 1 year in interventions of this type is uncertain as most studies have been short-term. The SPF project provided booster sessions in Year 2 to help maintain intervention effects. Booster sessions are one strategy to maintain intervention effects ${ }^{9-13}$ but have not been well studied in sun protection interventions. Results from the second year of follow-up are now reported in which the hypothesis that intervention effects could be maintained with minimal intervention is tested.

\section{Methods}

The SPF project was a cluster randomized trial that used block randomization to assign participating schools to either control or intervention status (Figure 1). Details of the intervention and study design have been previously reported. ${ }^{8}$ In Year 2, one intervention school withdrew from the study before the start of Year-2 data collection or intervention activities. The second-year intervention began with an introductory session with participating 5th-grade students where written assent to participate was obtained from students new to the program. Returning students were given their wide-brimmed hats (stored over the summer) while new students received two new hats (for school and at home). Students received a brief educational lesson that reestablished sun safety guidelines. Research assistants subsequently delivered at least two 60-minute interactive classroom sessions (late Fall, early Spring) that reinforced the importance and benefits of sun protection. Control schools had similar sessions that obtained written assent for new students and that targeted scientific topics other than sun protection.

As in Year 1, data were collected from student participants at three time periods in Year 2; fall, winter, and spring. The primary outcome of the study, hat use at school, was measured by direct observation based on methods described by Milne and colleagues. ${ }^{14,}{ }^{15}$ Hat use at times outside of school (a secondary outcome) was measured by self-report. ${ }^{16}$

An analysis of the impact of the intervention on skin pigmentation among a convenience sample of students (200 intervention, 239 control) who agreed to undergo additional measurements (fall, winter, spring, measured in Year 1 and 2) was conducted. ${ }^{8}$ Skin pigmentation (melanin index, range 0\%-100\%) was repeatedly measured on the forehead using a DermaSpectrometer (Cortex Tech., Hadsund Denmark). ${ }^{17,} 18$ At each measurement point (after the baseline measure), students' current melanin values were compared to their previous reading and categorized as either tanned (melanin value was greater) or nontanned (melanin value was the same or lower). Each student, therefore, could potentially contribute six measures of tanning.

Nevi counts are a marker of cumulative UV exposure and subsequent melanoma risk ${ }^{19,20}$ and have been successfully used as measures of cumulative UV exposure in other sun protection interventions. ${ }^{21-23}$ Nevi were assessed in areas protected by hats (the head and neck area) based on recommended methods of assessment. ${ }^{24}$ Inter-rater reliability of nevi 
count measurement between the project director and research assistants was assessed (correlation coefficients $0.89-0.96$ ).

\section{Statistical Analysis}

Two endpoints were examined: directly observed hat use at schools and self-reported hat use outside of schools measured at six time points over the 2-year study period. The clustered design was accounted for in the generalized linear mixed model. Allocation arm (intervention vs control), date of data collection (represented by a linear or quadratic term), and their interaction were included as fixed effects in the generalized linear mixed model. Several fixed covariates were tested in multivariable models as confounding factors (e.g., age, gender, race, and school uniform policy). Pigmentation changes were analyzed by use of a generalized linear mixed model. Nevi counts were similarly compared over time between intervention and control students using a generalized linear mixed model (PROC MIXED).

\section{Results}

Directly observed hat use at school is shown in Figure 2. Hat use remained essentially unchanged at control schools throughout the 2-year study period. At intervention schools there was an increase in observed hat use that peaked in the spring of Year 1 at $41 \%$ and then gradually diminished during Year 2 . Changes in hat use over time were significantly different for intervention students compared to control students $(p<0.0001$ for both linear and quadratic interaction terms, ICC $=0.002$ ). Self-reported use of hats while outside of school did not differ by the end of the study (control 9.9\%, intervention 11.5\%; $p=0.14$ for intervention effect, ICC $=0.00006$ ).

The likelihood that students tanned between observation sessions was explored among 439 students who provided comparison data (total of 1184 measures). Among intervention students, $42.0 \%$ of observations showed an increase in melanin from the prior value. Among control students, $45.6 \%$ of observations showed an increase in melanin from the prior reading. This difference was not significant $(p=0.94$, ICC $=0.001)$. Nevi counts were similar at baseline (control $\mathrm{M}=9.8$, intervention $\mathrm{M}=9.0$ ) and not significantly different at the end of the study (control $\mathrm{M}=9.1 ; 95 \% \mathrm{CI}=7.7,10.5$, intervention $\mathrm{M}=6.8 ; 95 \% \mathrm{CI}=5.6,8.0 ; p=0.07$ for changes in nevi counts over time comparing intervention and control students, $\mathrm{ICC}=0.0006$ ).

\section{Discussion}

Previous studies have attempted to change sun protection behaviors in elementary school settings, some successfully ${ }^{25-28}$, others less so. ${ }^{29-33}$ Interventions relying on single sessions with students have generally not proven successful ${ }^{29,34}$ while strategies that targeted students over the course of the school year have proven more successful. ${ }^{25,34}$

There are several possible reasons for diminished effects in Year 2. First, approximately $25 \%$ of students were new to the project in Year 2 and had not received the full intervention the previous year. Second, social norms that were developed over the course of the year encouraging hat use may have been disrupted in Year 2 as students were assigned to new classes with new peers. Finally, the effects of behavioral interventions often simply wane with time. ${ }^{35}$ The specific benefits of booster sessions could not be assessed, as participants were not randomly assigned to this intervention in Year 2.

The intervention did not lead to physiologic differences in the skin of targeted children. These measurements were conducted on a subgroup of participants, however, which may 
have biased the results. The increased use of hats at school appears unlikely to have been of sufficient magnitude to affect skin measures of the overall sample. It is also possible that UV exposure outside of school had greater impact on these measures than did exposures at school. Given these results, the ability of school-based interventions to prevent skin cancer is uncertain.

Strengths of this study include its group randomized design, the ability to affect hat use in the second year of follow-up, and the ability to measure this outcome through direct observation. Given the limited intervention effect, further research is needed to develop effective sun protection curricula and policies that permanently change the culture of sun protection at schools. As UV exposure during school hours is limited, it is also important that these efforts generalize to other settings, something this intervention was unable to demonstrate.

Given their broad reach, though, schools remain an attractive vehicle for delivering sun protection education to children. ${ }^{36,37}$ School-based interventions are one potential method of increasing hat use at schools while booster sessions can help address sustainability. Future research is needed on methods to more generally and permanently change the culture of sun protection in schools and to affect change in behaviors outside of school.

\section{Acknowledgments}

This project was supported by the National Cancer Institute [Grant number RO1 CA103965-01A2].

\section{References}

1. Truhan AP. Sun protection in childhood [corrected and republished article originally printed in Clin Pediatr (Phila) 1991 Jul;30(7):412-21]. Clin Pediatr. 1991; 30(12):676-681.

2. Preston DS, Stern RS. Nonmelanoma cancers of the skin. N Engl J Med. 1992; 327(23):1649-1662. [PubMed: 1435901]

3. Godar DE. UV doses of American children and adolescents. Photochem Photobiol. 2001; 74(6): 787-793. [PubMed: 11783934]

4. Godar DE. UV doses worldwide. Photochem Photobiol. 2005; 81(4):736-749. [PubMed: 15819599]

5. American Academy of Pediatrics Committee on Environmental Health. Ultraviolet Light: A Hazard to Children. Pediatrics. 1999; 104:328-333. [PubMed: 10429020]

6. Gallagher RP, Hill GB, Bajdik CD, et al. Sunlight exposure, pigmentary factors, and risk of nonmelanocytic skin cancer. I. Basal cell carcinoma. Arch Dermatol. 1995; 131(2):157-163. [PubMed: 7857111]

7. Berneburg M, Surber C. Children and sun protection. Br J Dermatol. 2009; 161 Suppl 3:33-39. [PubMed: 19775355]

8. Hunter S, Love-Jackson K, Abdulla R, et al. Sun protection at elementary schools: a cluster randomized trial. J Natl Cancer Inst. 2010; 102(7):484-492. [PubMed: 20332388]

9. De Greef K, Deforche B, Tudor-Locke C, De Bourdeaudhuij I. A cognitive-behavioural pedometerbased group intervention on physical activity and sedentary behaviour in individuals with type 2 diabetes. Health Educ Res. 2010; 25(5):724-736. [PubMed: 20338978]

10. Botvin G, Renick N, Baker E. The effects of scheduling format and booster sessions on a broadspectrum psychosocial approach to smoking prevention. J Behav Med. 1983; 6(4):359-379. [PubMed: 6668603]

11. Wu Y, Stanton BF, Galbraith J, et al. Sustaining and Broadening Intervention Impact: A Longitudinal Randomized Trial of 3 Adolescent Risk Reduction Approaches. Pediatrics. 2003; 111(1):e32-e38. [PubMed: 12509592]

12. Hollis JF, Polen MR, Whitlock EP, et al. Teen Reach: Outcomes From a Randomized, Controlled Trial of a Tobacco Reduction Program for Teens Seen in Primary Medical Care. Pediatrics. 2005; 115(4):981-989. [PubMed: 15805374] 
13. Lederman RP, Chan W, Roberts-Gray C. Parent-adolescent relationship education (PARE): program delivery to reduce risks for adolescent pregnancy and STDs. Behav Med. 2008; 33(4): 137-143. [PubMed: 18316271]

14. Milne E, Corti B, English R, Cross D, C C, Johnston R. The use of observational methods for monitoring sun-protection activitities in schools. Health Educ Research. 1999; 14:167-175.

15. Milne E, English DR, Corti B, et al. Direct measurement of sun protection in primary schools. Prev Med. 1999; 29(1):45-52. [PubMed: 10419799]

16. Hunter S, Wells KJ, Jacobsen PB, et al. Assessment of Elementary School Students' Sun Protection Behaviors. Pediatr Dermatol. 2009; 27(2):182-188. [PubMed: 19686304]

17. Clarys P, Alewaeters K, Lambrecht R, Barel AO. Skin color measurements: comparison between three instruments: the Chromameter, the DermaSpectrometer, and the Mexameter. Skin Res Technol. 2000; 6(4):230-238. [PubMed: 11428962]

18. Shriver MD, Parra EJ. Comparison of narrow-band reflectance spectroscopy and tristimulus colorimetry for measurements of skin and hair color in persons of different biological ancestry. Am J Phys Anthropol. 2000; 112(1):17-27. [PubMed: 10766940]

19. Luther $\mathrm{H}$, Altmeyer $\mathrm{P}$, Garbe $\mathrm{C}$, et al. Increase of melanocytic nevus counts in children during 5 years of follow-up and analysis of associated factors. Arch Dermatol. 1996; 132(12):1473-1478. [PubMed: 8961877]

20. English DR, Armstrong BK. Melanocytic nevi in children. II. Observer variation in counting nevi. Am J Epidemiol. 1994; 139(4):402-407. [PubMed: 8109574]

21. Autier P, Dor JF, Ng S, et al. Sunscreen use and duration of sun exposure: a double-blind, randomized trial. J Natl Cancer Inst. 1999; 91(15):1304-1309. [PubMed: 10433619]

22. Autier P, Dore JF, Cattaruzza MS, et al. Sunscreen use, wearing clothes, and number of nevi in 6to 7-year-old European children. European Organization for Research and Treatment of Cancer Melanoma Cooperative Group. J Natl Cancer Inst. 1998; 90(24):1873-1880. [PubMed: 9862624]

23. Milne E, English DR, Cross D, Corti B, Costa C, Johnston R. Evaluation of an intervention to reduce sun exposure in children: design and baseline results. Am J Epidemiol. 1999; 150(2):164173. [PubMed: 10412961]

24. English, DR.; MacLennan, R.; Rivers, JK.; Kelly, J.; Armstrong, BK. IARC Internal Report No. 90/002. France: Lyon; 1990. Epidemiological studies of melanocytic naevi: protocol for identifying and recording naevi.

25. Giles-Corti B, English DR, Costa C, Milne E, Cross D, Johnston R. Creating SunSmart schools. Health Educ Res. 2004; 19(1):98-109. [PubMed: 15020549]

26. Milne E, English DR, Johnston R, et al. Reduced sun exposure and tanning in children after 2 years of a school-based intervention (Australia). Cancer Causes Control. 2001; 12(5):387-393. [PubMed: 11545453]

27. Milne E, Johnston R, Cross D, Giles-Corti B, English DR. Effect of a school-based sun-protection intervention on the development of melanocytic nevi in children. Am J Epidemiol. 2002; 155(8): 739-745. [PubMed: 11943692]

28. English DR, Milne E, Jacoby P, Giles-Corti B, Cross D, Johnston R. The effect of a school-based sun protection intervention on the development of melanocytic nevi in children: 6-year follow-up. Cancer Epidemiol Biomarkers Prev. 2005; 14(4):977-980. [PubMed: 15824173]

29. Gooderham MJ, Guenther L. Sun and the skin: evaluation of a sun awareness program for elementary school students. J Cutan Med Surg. 1999; 3(5):230-235. [PubMed: 10381945]

30. Barankin B, Liu K, Howard J, Guenther L. Effects of a sun protection program targeting elementary school children and their parents. J Cutan Med Surg. 2001; 5(1):2-7. [PubMed: 11281429]

31. Buller DB, Buller MK, Beach B, Ertl G. Sunny days, healthy ways: evaluation of a skin cancer prevention curriculum for elementary school-aged children. J Am Acad Dermatol. 1996; 35(6): 911-922. [PubMed: 8959950]

32. Grant-Petersson J, Dietrich A, Sox C, Winchell C, Stevens M. Promoting Sun Protection in Elementary Schools and Child Care Settings: The SunSafe Project. J School Health. 1999; 69:100-106. [PubMed: 10332645] 
33. Naldi L, Chatenoud L, Bertuccio P, et al. Improving Sun-Protection Behavior among Children: Results of a Cluster-Randomized Trial in Italian Elementary Schools. The "SoleSi SoleNoGISED" Project. J Invest Dermatol. 2007; 26:26.

34. Buller DB, Taylor AM, Buller MK, Powers PJ, Maloy JA, Beach BH. Evaluation of the Sunny Days, Healthy Ways sun safety curriculum for children in kindergarten through fifth grade. Pediatr Dermatol. 2006; 23(4):321-329. [PubMed: 16918625]

35. Milne E, Jacoby P, Giles-Corti B, Cross D, Johnston R, English DR. The impact of the kidskin sun protection intervention on summer suntan and reported sun exposure: was it sustained? Prev Med. 2006; 42(1):14-20. [PubMed: 16330090]

36. Task Force on Community Preventive Services. Recommendations to prevent skin cancer by reducing exposure to ultraviolet radiation. Am J Prev Med. 2004; 27:467-470. [PubMed: 15556745]

37. Saraiya M, Glanz K, Briss PA, et al. Interventions to prevent skin cancer by reducing exposure to ultraviolet radiation: a systematic review. Am J Prev Med. 2004; 27(5):422-466. [PubMed: 15556744] 


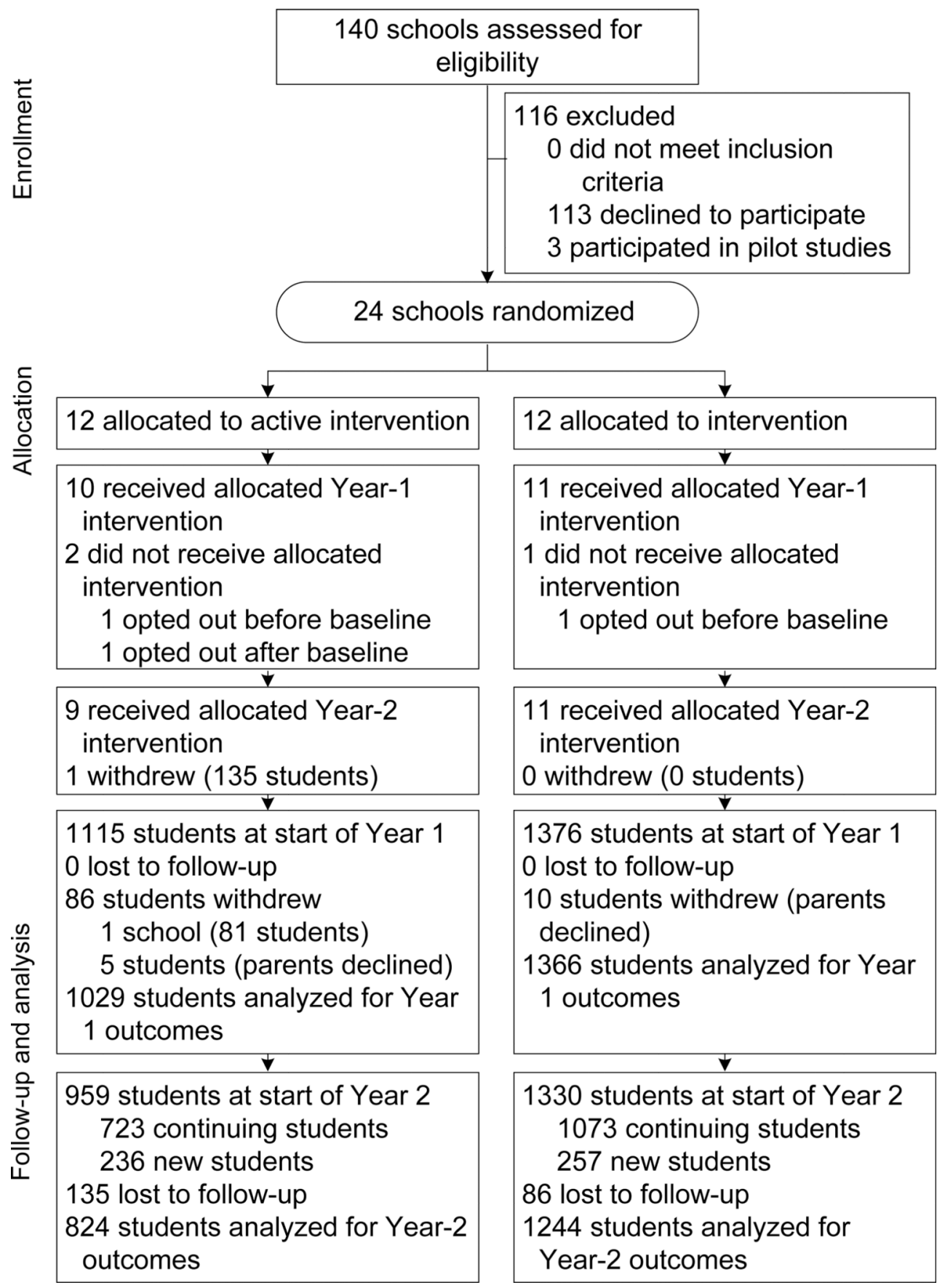

Figure 1.

Comparison of intervention and control schools in the Sun Protection for Florida's Children project 


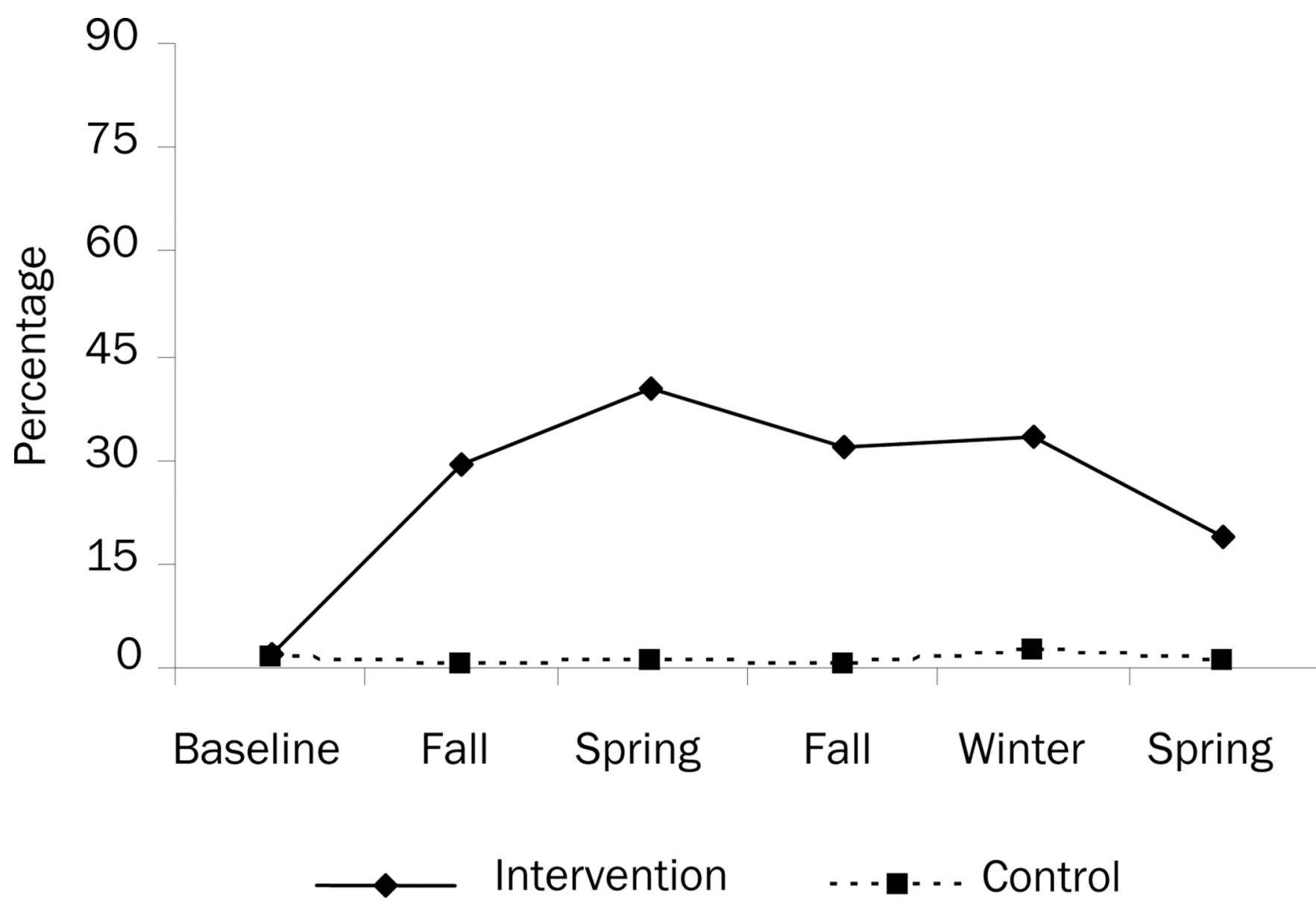

Figure 2.

Percentage of students directly observed wearing hats while at school 